\title{
Asymmetries in Experiential and Vicarious Feedback: Lessons from the Hiring and Firing of Baseball Managers
}

\author{
David Strang, ${ }^{a}$ Kelly Patterson ${ }^{b}$ \\ a) Cornell University; b) University of Southern California
}

\begin{abstract}
We examine experiential and vicarious feedback in the hiring and firing of baseball managers. Realized outcomes play a large role in both decisions; the probability that a manager will be fired is a function of the team's win-loss record, and a manager is quicker to be rehired if his teams had won more in the past. There are substantial asymmetries, however, in the fine structure of the two feedback functions. The rate at which managers are fired is powerfully shaped by recent outcomes, falls with success and rises with failure, and adjusts for history-based expectations. By contrast, hiring reflects a longer-term perspective that emphasizes outcomes over the manager's career as well as the most recent campaign, rewards success but does not penalize failure, and exhibits no adjustment for historical expectations. We explain these asymmetries in terms of the disparate displays of rationality that organizations enact in response to their own outcomes versus those of others. Experiential feedback is conditioned by a logic of accountability, vicarious feedback by a logic of emulation.
\end{abstract}

Keywords: performance feedback; vicarious learning; institutionalism; bounded rationality; hiring and firing; managerial succession

Editor(s): Jesper Sørensen, Olav Sorenson; Received: October 9, 2013; Accepted: October 14, 2013; Published: May 12, 2014

Citation: Strang, David and Kelly Patterson. 2014. "Asymmetries in Experiential and Vicarious Feedback: Lessons from the Hiring and Firing of Baseball Managers." Sociological Science 1: 178-198. D0I: 10.15195/v1.a13

Copyright: (C) 2014 Strang and Patterson. This open-access article has been published and distributed under a Creative Commons Attribution License, which allows unrestricted use, distribution and reproduction, in any form, as long as the original author and source have been credited.

Tam probably the only guy who worked

1 for Stengel before and after he was

a genius.

-Warren Spahn

Much research on organizational choice operates within the Carnegie School's concept of performance feedback (March and Simon 1958; Cyert and March 1963), sometimes referred to as adaptive learning or feedback-based learning. Like pigeons in a cage, organizations are likely to repeat actions that have been associated with desirable outcomes in the past and to avoid or discontinue actions linked to undesirable outcomes. Performance feedback places modest cognitive demands on real-world actors while generating sensible lines of action. This article links institutional accounts of the interpretation of performance to the rich tradition of feedback-based decision analysis, proposing that bounded rationality is usefully complemented by norms of rationality
(Meyer and Rowan 1977; Feldman and March 1981).

We consider two key forms of performance feedback - experiential and vicarious. Experiential feedback involves the organization's response to its own outcomes. Success leads decision makers to stay the course; if it's not broke, they don't fix it. In good times, apparently insightful business strategies are retained, leaders who deliver the goods are rewarded, and seemingly effective management techniques become valued traditions. Poor results, conversely, generate pressure for change and a search for a better mousetrap. Business strategies are torn up, leaders shown the door, and policies and programs reevaluated. This spare "win-stay, lose-shift" logic provides a robust baseline that undergirds research on evolving aspirations, updating rules, and performance sampling and highlights conditions that militate against adaptive response, such as the ability of well-placed corporate leaders to deflect blame for organizational failure. 
Vicarious feedback involves the same core notion of behavioral reinforcement, now applied to outcomes of others. The business models of successful peers are mimicked, their leaders or lieutenants recruited, and their management techniques emulated. Strategies and policies linked to failure elsewhere are avoided, and those who bear responsibility (or are simply in the wrong place at the wrong time) are shunned rather than sought out. Influential conceptualizations of mimesis within the institutional and ecological traditions (DiMaggio and Powell 1983; Haveman 1993) are grounded in the Carnegie School's notions of bounded rationality and problemistic search.

Performance feedback of both types is well documented. Manns and March (1978) provided perhaps the first explicit test of experiential feedback in a study of how university departments responded to financial adversity. A variety of studies exploring the underlying decision process and its organizational implications followed; of particular note is Greve's $(1998,2003)$ framework for modeling strategic change as a function of prior outcomes, which this article also employs. In the last decade, work on organizational responses to their own outcomes has been complemented by careful documentation of responses to outcomes achieved elsewhere (Haunschild and Miner 1997; Chuang and Baum 2003; Baum and Dahlin 2007; Kim and Miner 2007; Schwab 2007).

Though much research has investigated experiential and vicarious feedback, differences between the two mechanisms are seldom theorized. This article draws on institutional accounts (Meyer and Rowan 1977; Feldman and March 1981) to consider the symbolic aspects of performance feedback. We argue that responses to the organization's own outcomes are conditioned by a logic of accountability, whereas responses to the outcomes of others follow a logic of emulation. These distinct logics shape three dimensions of performance feedback examined here: the weight of recent versus temporally distant events, sensitivity to success versus failure, and adjustment to historically evolving expectations.

We test for asymmetries in experiential and vicarious feedback in models of managerial succession. Organizations act on the basis of experiential feedback, in our language, when they utilize realized outcomes in deciding whether to retain or dismiss their current managers. They utilize vicarious feedback when they use the outcomes of other organizations in identifying whom to hire. A first step in the analysis that follows shows that hiring and firing are systematically linked to prior performance. Our focus, however, is not on the existence of these relationships but on the fine structure of the two feedback functions.

It should be noted at the outset that performance feedback is just one component of multilayered personnel decisions, which also involve evaluations of ability based on monitoring (Ouchi and Maguire 1975) as well as nonmeritocratic factors. Organizations may reward managers whose numbers are poor because they are perceived to have been foiled by bad luck or plagued by the errors of others, because they have forged strong alliances with superiors, or because they have the desired background and bearing. Although these sorts of considerations are important, they pose substantial measurement challenges and in many cases are not readily theorized. We maintain a focus on outcomes not because they are the sole drivers of personnel decisions - they are not-but because prior performance is a major factor that is empirically accessible and generalizes well.

Why treat firing as influenced by the organization's own outcomes and hiring as influenced by the outcomes of others? Where the abandonment of current practice is concerned, the organization's experience is vivid and meaningful in a way that vicariously observed outcomes are not (Denrell and March 2001; Strang and Macy 2001). This logic applies with particular force to personnel decisions, for good administrative, strategic, and in some cases legal reasons. Managers carry a legitimate claim to be judged on their own merits and on the basis of outcomes realized on their watch. In the baseball context studied here, as in many but not all organizational settings, strong norms limit efforts to raid the managerial talent of peers.

Once a vacancy arises, by contrast, vicarious feedback moves to the fore. Outcomes achieved elsewhere provide a means of discriminating between potential candidates for the position. External hires lack a track record with the hiring firm until after it takes the plunge. And unless the organization is partitioned into separate divisions whose outcomes are substantially independent, experiential feedback cannot distinguish among internal candidates, all of whom stand in 
the same position relative to the performance of the firm as a whole 1

Much research points to poor outcomes as drivers of executive dismissal. In a detailed review, Kesner and Sebora (1994:356) noted that "the findings were consistent - succession rates were higher in low performing firms than in high performing firms." These effects are often large; for example, Puffer and Weintrop (1991) found that the strongest predictor of CEO turnover was the gap between financial performance and expectations. The impact of past performance on dismissal, often dubbed "obvious" or "common sense," is sufficiently salient that we have detailed models of its moderators (see Fredrickson, Hambrick, and Baumrin 1988).

There has been little work, by comparison, on the effects of vicariously observed outcomes on hiring. Organizational researchers have focused instead on successor characteristics such as the distinction between insiders versus outsiders and on the effects of turnover on subsequent performance (Kesner and Sebora 1994). Because most studies do not ask who is hired, there has been limited opportunity to introduce the candidate's track record into models of hiring. But Khurana's (2002) detailed analysis of executive succession suggested that strong effects may thereby be overlooked, finding that external CEO candidates were "categorized according to the performance of their current firms" and that directors "rarely cast a critical eye on the supposed connection between firm performance and executive quality..." (109). Khurana reported that $70 \%$ of outsider CEO appointments to Standard \& Poor's companies between 1978 and 1996

\footnotetext{
${ }^{1}$ Our focus on the hiring and firing of individual managers enforces the separation of experiential feedback in firing from vicarious feedback in hiring. If we were to examine the hiring and firing of types of managers instead, it would be feasible to introduce a full set of cross-effects. For example, analysis of the firing of a manager with a particular background or strategic orientation (call it type A) could consider both the organization's own experience and that of other organizations with type A, and hiring analyses could incorporate the organization's prior experience with type A managers as well as the average track records of managerial type $\mathrm{A}$ in other organizations. When we examine the same processes at the level of named individuals, however, firing decisions do not involve significant external comparisons (the manager in the hot seat does not possess clones elsewhere), and hiring decisions do not involve significant internal comparisons.
}

came from companies in the top performance quartile of their industries.

Our strategy is to treat experiential and vicarious feedback as possessing the same general form, sufficiently so that they can be analyzed via parallel modeling and measurement operations. We do so in an analysis of managerial succession in Major League Baseball, where the team's own record governs the firing decision while the records of others shape the decision of whom to hire. The latter analysis is limited to the rate at which ex-managers with prior major league experience are rehired, because first-time managers do not possess comparable track records to which hiring clubs can refer $2^{2}$ Examination of the hiring of first-time managers also poses significant design problems due to the lack of a well-defined risk set.

Methodological issues aside, the key benefit to focusing on firing vs. re-hiring is analytic leverage. The same individuals appear on both sides of the ledger, and in fact the same outcomes do as well. The record that gets a manager fired is the same as the one that gets him hired; each dismissed manager enters the risk set of potential hires carrying with him the track record that preceded his job loss, and it is on the basis of this track record that he succeeds or fails to obtain a new position. If the structure of performance feedback varies across the two decisions, it is not due to compositional or individual-specific differences but instead because assessments of the same performances depend on whether they are experienced directly or observed vicariously.

\section{Bounded Rationality and Norms of Rationality}

In the organizational literature, performance feedback is generally approached within the framework of bounded rationality. The Carnegie School (March and Simon 1958; Cyert and March 1963)

\footnotetext{
2 First-time managers are generally drawn from the ranks of ballplayers, bench coaches, scouts, and minor league managers, with $27 \%$ serving initially as player/managers. Team performance can only be assigned for minor league managers, and even here the developmental purpose of the league's farm system means that wins and losses are not the chief marker of success in this role.
} 
developed a broad critique of choice-theoretic models that posit maximization of utility across alternatives, emphasizing their heroic assumptions about human knowledge and calculating capacity. They contended that managers who are "intendedly rational, but boundedly so" could more plausibly employ simple rules that are consistent with information processing constraints. Rather than continuously optimize on the margin, decisionmakers limit the occasions that prompt reconsideration of previous choices, consider a defined set of options, and satisfice by selecting a feasible line of action. Performance feedback provides a key application of these ideas, both in identifying choice points (outcomes that fall below the organization's aspiration level) and directions for change (behaviors that have worked in the past).

Bounded rationality is relevant to management hiring and firing. Managers contribute significantly to organizational outcomes, and decision makers at every level are motivated to place authority in capable hands. But managerial quality is difficult to assess. The indirect, mediated nature of managerial work impedes assessment; managers achieve results with and through others ${ }^{3}$ Power dynamics and rivalry also make it hard for "higher ups" to take the recommendations of a manager's peers or subordinates at face value. Given substantial inferential challenges, boundedly rational decision makers are likely to treat realized outcomes as proxies for poorly observed managerial quality and to link hiring and firing to past performance.

Rationality is more than an adequate relationship between means and ends, however; it is also a standard by which audiences evaluate organizations. From an institutional perspective, organizations gain resources and improved life chances when they conform to widely held understandings of rational action (Meyer and Rowan 1977). While formal structure is conventionally argued to serve this ceremonial function, decisions can play the same role - see Feldman and March's (1981) account of why data are often collected but not used. By responding to per-

3 In the baseball domain, player contributions are assessed by a bevy of individual-level measures - not just batting averages and strikeouts but UZR, OPS, VORP, WAR - while no equivalent measures of a skipper's acumen exist. formance in readily comprehended and socially approved ways, decisionmakers display rationality to key audiences. When such displays are made in a convincing manner, the organization is better positioned to retain or gain the support of stakeholders, even if subsequent outcomes are unsatisfactory.

Responses to performance are thus themselves "performances" subject to norms of rationality. Organizational leaders earn symbolic credit when their actions are appropriately responsive to significant events. The decision to change course when bad things happen is one of the clearest signals a leader can send; to fail to act in such circumstances is to appear dogmatically inflexible or "asleep at the wheel." Managerial hiring and firing are among the most powerful levers available to organizational decision makers and a visible opportunity for them to display rationality.

The norms that surround performance have a moral component as well. In a culture that celebrates individual ability, skill, and effort as intrinsically valuable and the ultimate determinants of collective outcomes (Meindl, Ehrlich, and Dukerich 1985), decisions to reward the successful and punish the failure are not only pragmaticthey are just. The organization acts in accordance with a moral concept of personal responsibility when it replaces the manager who recently presided over disaster with one who has earned the opportunity to take the helm. Even when individual control over events is acknowledged to be limited, rewards and punishments that align with outcomes can be applauded as sending the right message.

An institutional perspective draws attention to the organization's audience (Zuckerman 1999). Leadership decisions are disciplined by the views of outsiders who are in a position to withhold valued resources if appropriate action - from their standpoint - is not taken, and organizational leaders frame their actions and achievements to impress various constituencies (Staw, McKechnie, and Puffer 1983). In the baseball context studied here, it is natural to think primarily of the fans, voluntary supporters who lavish enthusiasm and spending on the team, although other audiencesinvestors, sportswriters, pundits - may also be relevant. 
We assume that personnel decisions are shaped by technical as well as the normative features of rationality but emphasize the latter because they help theorize asymmetries in experiential and vicarious feedback. An organization's response to its own performance, we argue, follows a logic of accountability (see Lerner and Tetlock [1999] for a review of related psychological research and Jensen [2006] for application to management decisions). Organizational leaders dramatize concern for poor outcomes when they fire managers in a downturn and celebrate good outcomes when they reward those who have achieved success. The often ritualized morality play that attends organizational success and failure is bolstered by the organization's audience, whose members are well aware of small changes in collective fortunes and expect appropriate action to be taken.

Vicarious feedback, by contrast, is animated by a logic of emulation (Strang and Macy 2001). Organizations focus on the positive model provided by peers and competitors, seeking to acquire or imitate the secrets of their success. Accountability for poor performance does not arise where external outcomes are concerned - a downturn elsewhere is someone else's problem and one that holds little interest for the hirer's audience. It is instead the external success story that is salient: well publicized, competitively threatening, and the germ of a positive solution. Decision makers offer audiences a public display of commitment and vision when they hire managers who have achieved success elsewhere.

Logics of accountability versus emulation rest on the disparate social meanings of experiential and vicarious performance rather than their common relevance for assessments of managerial quality. While bounded rationality (in the sense of cognitive limitations) should influence the two decisions in parallel ways, sociological considerations imply asymmetries in the fine structure of experiential and vicarious feedback. The track record that gets a manager fired should not be the inverse of the one that gets him hired. In the following, we employ these ideas to develop hypotheses concerning three observable dimensions of performance feedback: rates of temporal discounting, sensitivity to success versus failure, and adjustment for historical expectations.

\section{Temporal Discounting}

We expect experiential feedback to be dominated by a short-term orientation, whereas vicarious feedback takes the longer view. In both cases, recent performance should count for more than events in the distant past (Greve 2003). But the rate of temporal discounting should be higher when the organization's own outcomes are concerned than when the outcomes of others are at issue.

The accountability of responsible decision makers for their own organization (Jensen 2006) fastens attention on current outcomes. When results are unsatisfactory, leaders are expected to put personal attachments aside and make tough personnel calls. Indeed, the organizational imperative to act is so strong that it may override recognized merit - a universally respected skipper can be dismissed in accordance with the credo that "something has to be done" and that the organization will benefit from "a fresh start." When outcomes are favorable, success washes away a history of disappointments, fostering a climate in which even the most mediocre manager is rewarded.

The ethical obligations of organizational leaders point in the same direction. It is churlish for a club to treat a successful field manager, just returned from a hero's journey, as if he had not brought home the prize. It is worse - not just distasteful but suspect - to give a generous raise and contract extension to a loser. Deviations from the moral imperative to reward success and punish failure put leadership's own integrity into question: perhaps the general manager cares more about his cronies than about the team or the fans.

This short-term orientation is enforced by the rapt attention of external stakeholders to recent outcomes. In the sporting arena studied here, the agony of a losing streak ("another night, another fright" in the immortal words of Natalie Jacobson) generates rising calls for change. Managers are a natural target of the fan's ire when things are going badly - the disasters that accompany strategic missteps are visible to all, and it is the manager qua strategist and motivator who absorbs symbolic responsibility for defeat. If the team is winning, contrariwise, managerial 
stratagems appear inspired (they almost always work!) and player handling adroit.

Where performance elsewhere is at issue, decision makers can afford a temporally balanced view. Today's outcome is just another data point, not an achievement that demands celebration or a problem that needs to be fixed. Recent outcomes should carry more weight than distant ones because they are more cognitively accessible and provide better proxies for underlying quality - a once winning manager may possess skills relevant to an earlier era or may simply have "lost it." But all outcomes retain information value. Memories of the past triumphs of rivals grow dim, but they are not made irrelevant by succeeding events in the way that today drives out yesterday in the organization's own experience.

The distance of organizational leaders and audiences from vicariously observed outcomes means that while hiring organizations may be applauded for learning from events elsewhere, they are not castigated if they decline to do so. Indeed, a decision maker may plausibly reject the culturally demeaning status of "mimic," point out that population heterogeneity and organizational traditions militate against a policy of following the herd, and courageously disregard the lessons proffered by performance. The general manager who gives the unsuccessful skipper of another club a second chance is in a more defensible position than the one who allows a loser to remain at the helm.

\section{Attention to Success versus Failure}

We expect experiential feedback to be dominated by responses to failure and vicarious feedback to be dominated by responses to success. Organizations should be influenced by all four possible outcomes, but the balance between responsiveness to positive and negative results is likely to shift with the decision maker's vantage point.

The first part of this argument is consistent with Cyert and March's (1963) notion of problemistic search. Organizational failure is midwife to organizational change. Bounded rationality prevents decision makers from optimizing continuously on all fronts. When all is well, managers conserve scarce resources and accumulate slack. When outcomes are unsatisfactory, leaders swing into action to do battle with inertia; the worse the outcomes, the quicker they are to act (though see Staw, Sandelands, and Dutton [1981] for the opposite prediction).

Accountability for organizational outcomes augments the emphatic response to negative events. Remedial measures are taken not only to repair very real problems but to demonstrate to interested audiences that corrective measures are being taken. Decision makers are not expected to be infallible, but they are expected to change course when results are unsatisfactory. Unwillingness to take action in bad times is the signature of weak leadership, whereas expectations about how leaders should respond to success are more amorphous and less morally fraught.

Strong norms of accountability culminate in scapegoating (Gamson and Scotch 1964; Boeker 1992). When results are poor, someone or something must be to blame - and personal liabilities make for a more compelling diagnosis than bad luck or adverse circumstances, particularly in a highly individualist culture. By holding the field manager responsible, general managers and owners act in accordance with a romantic conception of leadership (Meindl et al. 1985) while simultaneously letting the team and themselves off the hook.

Where vicarious feedback is concerned, the polarity is reversed. A logic of emulation draws attention to high performers and the secrets of their success, while poor performers lie under the radar. The success of rivals poses a competitive threat that demands attention and a positive example from which decision makers are primed to learn. External failure is unthreatening and uninformative - the negative example it offers (a rival $\operatorname{did} X$ and it didn't work) appears unhelpful to those in search of a winning formula (though see Baum and Dahlin [2007] and Kim and Miner [2007] on learning from dramatic cases of external failure like railroad crashes and bankruptcy).

The structure of audience attention bolsters efforts to replicate external success. Peers who achieve good outcomes are widely discussed in the mass media, a pattern of reporting that turns the human architects of victory into vividly delineated heroes. By acquiring the services of managers who have triumphed elsewhere, decision makers make a powerful (and sometimes expensive) public statement of faith in their organizations' future. Few will second-guess the 
leader who attracts a proven "winner" to the team.

Imitation of external success, while not often studied in hiring, is well documented in the broader literature on innovation diffusion. Major episodes of long-distance practice transfer, like the spread of Japanese quality techniques to the United States and European efforts to duplicate Silicon Valley-like industrial clusters, arise in the wake of large performance gains. The widespread practice of benchmarking - where organizations self-consciously study and imitate the "best in class" - provides an institutionalized version of the tendency to treat positive evidence as providing valuable information while neglecting negative evidence. Strang (2010) showed that managers constructed proposals for innovation by combining their own firms' poor results (which motivated the need for change) with the good results of external firms (which lent credibility to new courses of action); change agents were cognizant of internal successes and external failures but found them less helpful.

\section{Adjustment for Evolving Expectations}

An organization's current outcomes are likely to be interpreted in light of expectations based on prior performance, while analogous expectations should play a smaller role in vicarious feedback ${ }^{4}$ In both cases, dramatic historical reversals should be rewarded; the manager who takes a bunch of misfits from "worst to first" receives a special kind of celebration, one different in kind and greater than the skipper who continues a winning tradition. But we expect adjustment for prior performance to be stronger when organizations evaluate their own outcomes than when they observe those of others.

Broad differences in audience attention and displays of leadership are once again at work. Where the organization's own experience is concerned, the intense scrutiny with which stakeholders track outcomes incorporates both absolute results and the direction of change. A manager gets credit for righting the ship, even if the de-

\footnotetext{
${ }^{4}$ History-based standards are variously called targets, aspirations, or expectations. We use the term expectation for consistency across observation of one's own outcomes and the outcomes of others.
}

sired destination is still a long way off. One who presides over a falloff in the performance of a perennial champion is liable to be punished for an outcome that a mediocre club would welcome.

Where hiring is concerned, by contrast, historybased expectations play a lesser role. Expectations are cognitively expensive - it is straightforward to observe performance after the fact, whereas a subjectively meaningful expectation implies attention to events over time and concern for what is likely to happen. In accordance with a logic of emulation, leaders and audiences prefer to hire "winners" rather than "improvers."

The argument is supported by the literature and its silences. Much work on experiential feedback finds that current outcomes are evaluated relative to aspirations based on prior performance. Cyert and March (1963) defined the organization's target $G$ as a weighted moving average of performance $P$ :

$$
\begin{aligned}
G_{t} & =\alpha G_{t}+(1-\alpha) P_{t-1} \\
& =(1-\alpha) \sum s=1, \infty \alpha^{s-1} P_{t-s}
\end{aligned}
$$

Greve $(1998,2002)$ established that historical expectations or aspirations measured in this way define a discontinuity in the relationship between organizational performance and organizational change $5^{5}$ Puffer and Weintrop (1991) showed that $\mathrm{CEO}$ turnover is a function of the performanceexpectations gap rather than low performance per se. By contrast, we are unaware of research that demonstrates - or perhaps more revealingly, research that investigates - the impact of expectations on vicarious feedback.

Differential adjustment for expectations is consistent with and further specifies the disparity in temporal discounting postulated earlier. Ex hypothesi, experiential feedback involves rapid temporal discounting coupled with attention to short-term shifts in outcomes. Vicarious feedback involves less temporal discounting and diminished sensitivity to short-run changes in direction. Experiential feedback considers the derivative of the performance function; vicarious feedback calculates the integral.

\footnotetext{
5 This modeling framework is doubly useful in the following because it speaks not only to the effect of historybased expectations but also to relative attention to success and failure, conceptualized as outcomes above and below the target.
} 


\section{Methods}

Professional athletics provides a strategic research site for studies of performance feedback. Outcomes are well defined, meticulously recorded, and directly comparable across teams and over time. The great premium that competitive sports places on results - where, in a sense unmatched in the corporate world, "winning" is the product or service - means that subtle forms of performance feedback are likely to leave traces in observed behavior. There is limited scope (though not zero scope) for deft impression management to blunt the impact of failure on professional reputations.

As the capstone division in its sport, Major League Baseball (MLB) also provides a strategic setting for a study of the circulation of elites. There is no higher-status league to which successful managers can move nor better positions within the executive suite to which they may reasonably aspire. As a result, managers are unlikely to leave big league posts for better jobs elsewhere and are liable to reenter the managerial ranks when the opportunity arises. The fact that big league managers sit at the top of vacancy chains is particularly significant in light of informational limitations on types of moves, as discussed later.

We obtained data on organizational performance and managerial tenures from the website Baseball-Reference.com, one of the most detailed archival sources in a field famous for its obsession with statistics. Launched in 2000 by a former math professor at Saint Joseph's University, the site provides year-by-year records of every team, manager, and player in the history of the sport (Sports Reference LLC 2008). Team performance and managerial tenure data were extracted from 1901 (when the American League was formed, generally taken as the beginning of modern baseball) to 2008. In all, 475 individuals managed one or more games in the big leagues during this period. Of these, our study focuses on the 389 managers who were MLB skippers at the outset of at least one season and on the 687 distinct organizational tenures that these individuals experienced.

Analyses of firing work with the timing of 655 events (censored spells include teams at the close of the observation period, teams that dissolve, and instances of individual mortality). The hazard of firing is almost linear once we adjust for the high frequency of end-of-season moves. About three-fourths of big league managers were still at the helm after a year, about half after two years, and about a quarter after four years. Less than 10 percent of managers enjoyed tenures of more than 6 years, whereas Connie Mack served 50 years at the helm of the Philadelphia Athletics.

Analyses of hiring examine the rate at which ex-managers return to big league posts, an event that occurs 298 times. In contrast to exit, hiring rates decline markedly with time in the unemployment or "waiting" pool. Approximately 20 percent of all ex-managers were back in the saddle after a year, and 30 percent after two years. In total, 43 percent of all unemployment spells ended with the manager regaining a position as a MLB skipper. Among those with multiple tenures, 50 percent held two positions, 23 percent held three, and 15 percent held four. Billy Martin is the most frequently rehired manager in MLB history to date, with nine distinct tenures over a 20-year career.

The major limitation of baseball data is difficulty in discriminating between voluntary and involuntary separations, a perennial issue in studies of managerial succession. Shifts in formal incumbency are readily observed while the motives that lie behind them are not known. To assess the relative frequency of different forms of turnover, we conducted a web-based search of media discussions surrounding the 26 managerial departures that occurred between 2005 and 2007 as well as a random sample of 20 departures from previous years. In both groups, the great majority of events were initiated by the baseball club. Forty of the 46 managers (86 percent) were reported to have been fired or forced out, whereas the other 6 retired or quit. The rarity of these latter moves was also reflected in the surrounding commentary. For example, Mike Hargrove's 2007 decision to leave the red-hot Seattle Mariners because of his fading passion for the game was met with incredulity by the baseball world. None of the 46 cases involved the poaching of managers by other big league teams, a common occurrence when leagues of unequal stature are involved but a counternormative event within MLB itself.

We thus model managerial turnover as a firing process driven by the team's record. The competing risk of individually driven retirements/quits is real but small and controlled in part by the 
inclusion of covariates for age and career length. Although information distinguishing between voluntary and involuntary separations would provide more precise estimates, its absence makes for a conservative test of hypothesized relationships. To the extent that some managers voluntarily leave their posts when good outcomes would lead the organization to retain them, the negative effects of recent performance will be underestimated, and any bias toward experiential feedback from failure will be muted.

In analogous fashion, we treat all ex-managers as at risk of regaining a major league post, although some may in fact be unwilling to return at any price. Occupants of the waiting pool do not literally wait; some work in other posts in baseball, some sell cars or open restaurants, and still others go fishing. But because MLB managers stand at the top of their vacancy chain, there are few positions that ex-managers can hope to obtain that would be preferable to regaining a big league post. A web search of the 14 experienced managers who were rehired during the 2005 to 2007 period found that 5 moved directly to a new team before the beginning of the next season, 4 worked as coaches on big league clubs, 2 worked as big league scouts, 2 worked as broadcasters, and 1 worked as an insurance salesman. Once again, measurement error makes for a conservative testif some successful ex-managers would rather not return to the joys of field generalship and the camaraderie of the locker room, our models will underestimate the role of vicarious feedback.

One series of performance measures is based on team wins and losses, the outcomes for which field managers are responsible (other valued outcomes, such as financial profit, are the province of the executive office and general manager). Wonlost record, most recent period gives team victories divided by games played in the latest managerial spell. In the case of firing, it refers to the current season; in the case of hiring, to the season when the now unemployed manager had his most recent turn at the helm. Won-lost record, recent tenure gives the team's average results over the manager's years with that club, whereas won-lost record, career gives the performance of all teams managed by that skipper. Measures of performance above and below expectation/aspiration levels are formed as in Equation (1) and estimated via a grid search.
We also develop a second set of performance measures that describe the occurrence of markedly positive or negative outcomes. Dramatic success is indexed as the winning of a title - the World Series, the league pennant, and (after divisional play began in 1969) division title. Dramatic failure occurs when a team occupies the cellar in its league or division. These measures are calculated for the most recent spell (title, recent period; last place, recent period) and are also averaged over the manager's most current tenure and career (title, tenure and title, career; last place, tenure and last place, career).

A series of time-varying indicators capture influences on hiring and firing other than organizational performance. For managers who hold positions in a given year, tenure is the number of years at the helm of the manager's current club and career experience the sum of years as a big league skipper across all teams. We take the manager's age from biographical data provided by Baseball-Reference.com and remove individuals from the relevant risk sets upon their deaths. Additional controls include player/manager status and indicators for four historical eras in baseball (the birth of the major leagues from 1901 to 1919; the post-Black Sox era of strong commissioners from 1920 to 1945; the postwar boom accompanied by the decline of the minor leagues from 1946 to 1975; and the free agent era from 1976 to 2008). Table 1 gives descriptive statistics.

Managerial hiring and firing are modeled in an event history framework. We estimate Cox models (i.e., proportional hazards models estimated by partial likelihood) of the rate at which managers lose and regain positions. This flexible approach to time dependence allows us to incorporate both mid-season and off-season events and adjusts for the tendency for moves to cluster after the year's campaign is complete. Coefficients can be given a relative risk interpretation as multiplying the baseline hazard that a manager will experience the relevant hiring or firing event for a given shift in covariate values.

Firing analyses examine the first such event in a given year for each team ${ }^{6}$ Hiring analyses examine the rate at which ex-managers regain

\footnotetext{
6 Managers hired in mid-season are often engaged on a caretaker basis. A few such assignments are whimsical; for example, Ted Turner managed the team he owned, the Atlanta Braves, for a single game in 1977. Caretaker
} 


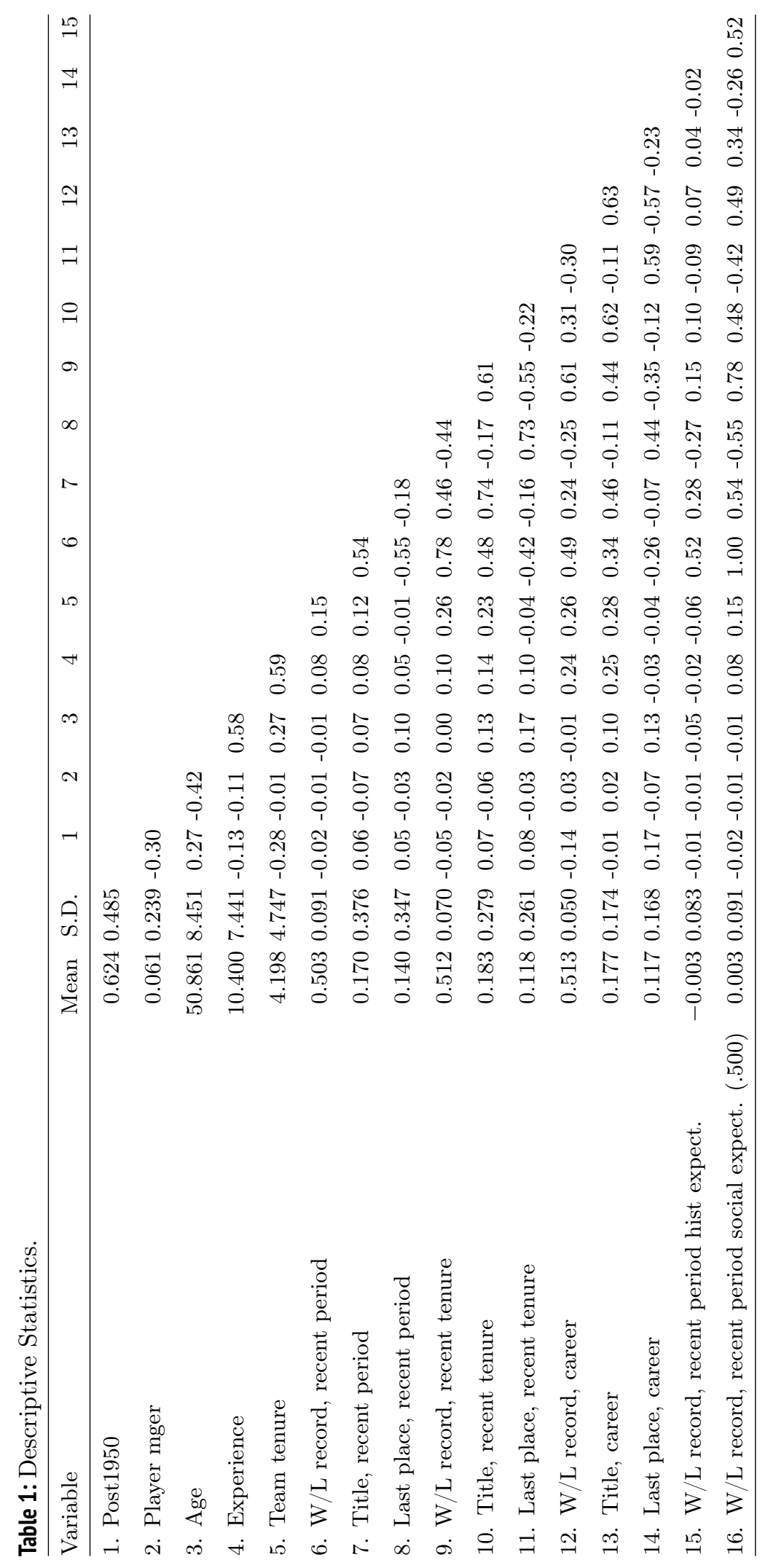


positions in the major leagues based on their prior records. If they have not been rehired, unemployed managers are censored 11 years after surrendering their most recent position; some such upper limit is useful in limiting the analysis to viable candidates, and sensitivity analyses indicate no qualitative impact on results across a range of reasonable values.

\section{Results}

We begin by charting the effects of the team's record in the immediately prior period on firing and hiring. Figure 1 plots the relationship between each season's won-lost record and the probability that the manager will depart; Figure 2 plots the relationship between the record of the ex-manager's last team and the probability that he will gain a new post. The graphs give the empirical frequency of the event (cases grouped by intervals of 0.05 on the team's won-lost record) and the estimated effect of recent performance in bivariate logistic regressions.

Figure 1 shows a strong, virtually linear relationship between the team's performance and the chance that the manager will depart. When teams win only one-third of their games, their managers have a 50 percent chance of losing their jobs. The probability of a skipper's departure falls to 22 percent when teams fight to an even record and to 12 percent when teams win 60 percent of the time. There is little sign of an imbalance in responsiveness to success or failure, with the possible exception of the extreme low end. The probability of dismissal flattens as we move from merely bad teams to truly horrendous ones, though such cases are not only wretched but mercifully few.

Figure 2 indicates that hiring is also systematically related to performance viewed vicariously from the perspective of the hiring organization. But the connection here is more modest; employment chances improve slightly as we move across the outcome distribution. Managers whose teams won one-third of their games have a 4.5 percent chance of being rehired, whereas those who batted .500 have a 7.9 percent chance. Only the truly outstanding performers - managers whose

managers, whether frivolous or not, are not subject to the same performance expectations as are regular managers. last team posted a record of .600 or better (97 + wins over 162 games) - show a marked rise in their employment prospects, which climbs to over 20 percent.

Across the range of performance outcomes, the impact of a team's most recent outcomes on firing is thus about 50 percent larger than that of another team's outcomes on hiring. The marked upswing in hiring probabilities for high performers is also consistent with the hypothesized success story bias in vicarious feedback. Firing based on directly experienced outcomes appears more evenly responsive to outcomes across the performance distribution-note how closely the regression line tracks observed frequencies of dismissal.

\section{Temporal Discounting}

To test for asymmetries in experiential and vicarious feedback while controlling for other factors, we develop multivariate hazard models of firing and hiring. A first set of analyses measure performance outcomes over various durations - the manager's most recent season, his tenure with that team, and his career record to date. To better distinguish the relative impact of team outcomes across multiple durations, we restrict attention to managers after their first year in the major leagues because there is no variation in performance for the most recent period, recent tenure, and career in the manager's first year as a big league skipper.

The first columns of Table 2 examine firing. Model 1, which does not include team performance, points to sensible regularities. The probability of a separation rises with age but falls with career length, suggesting a balance between increasing wisdom and flagging energy. The low rate of firing for long-tenured managers (six years or more) may signal the growth of cityspecific reputations. Player/managers experience a higher likelihood of separation and the hazard generally declines across historical eras, though these effects are not statistically significant.

Team performance adds enormous explanatory power to analyses of managerial firing. Net of covariates, the team's won-lost record in the most recent period sharply diminishes the probability of a managerial separation. For example, an improvement of 1 standard deviation $(0.09$, 


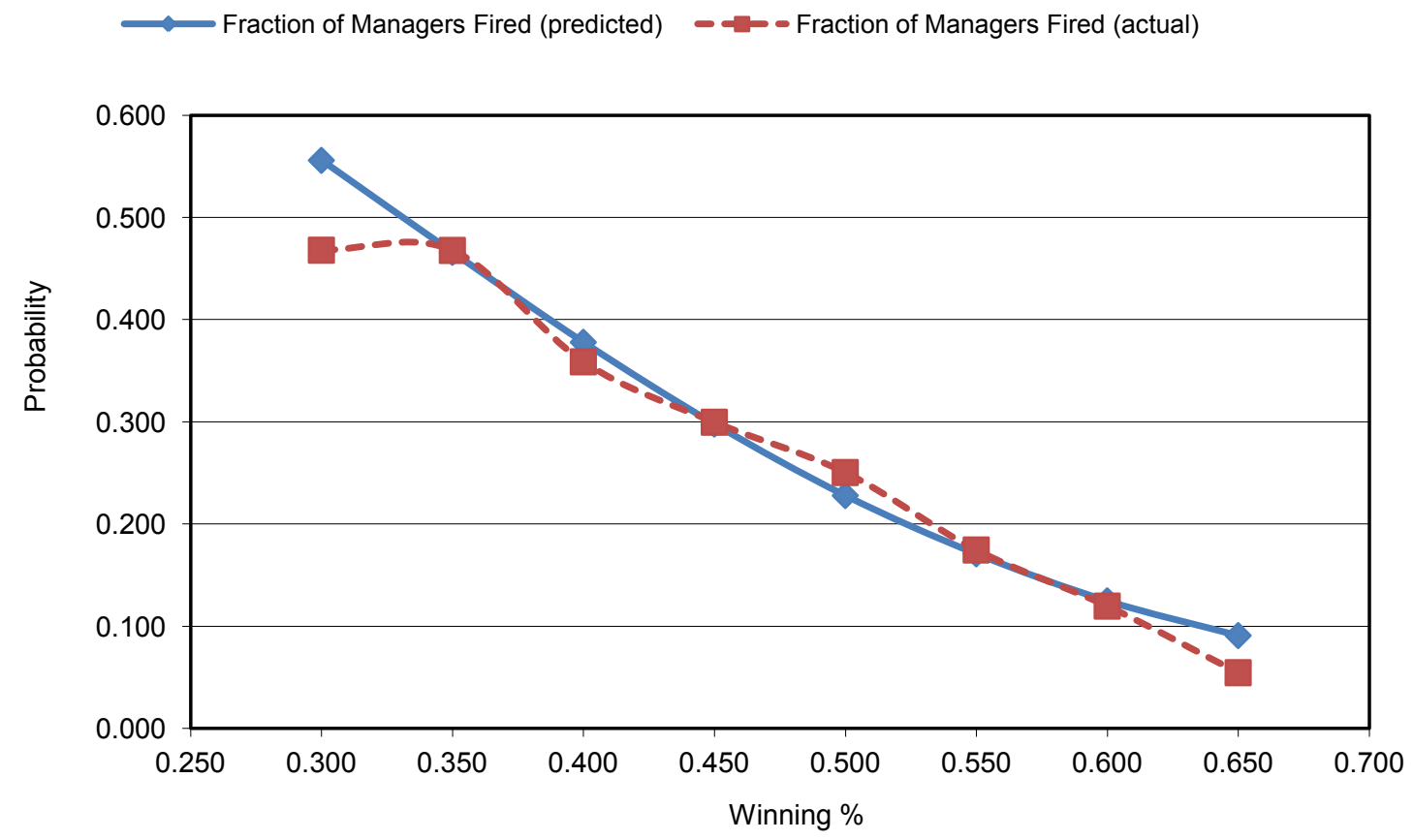

Figure 1: Probability that a Major League Baseball manager will be fired.

$-\Delta$ Fraction of Managers Hired (predicted) $\quad-\infty-$ Fraction of Managers Hired (actual)

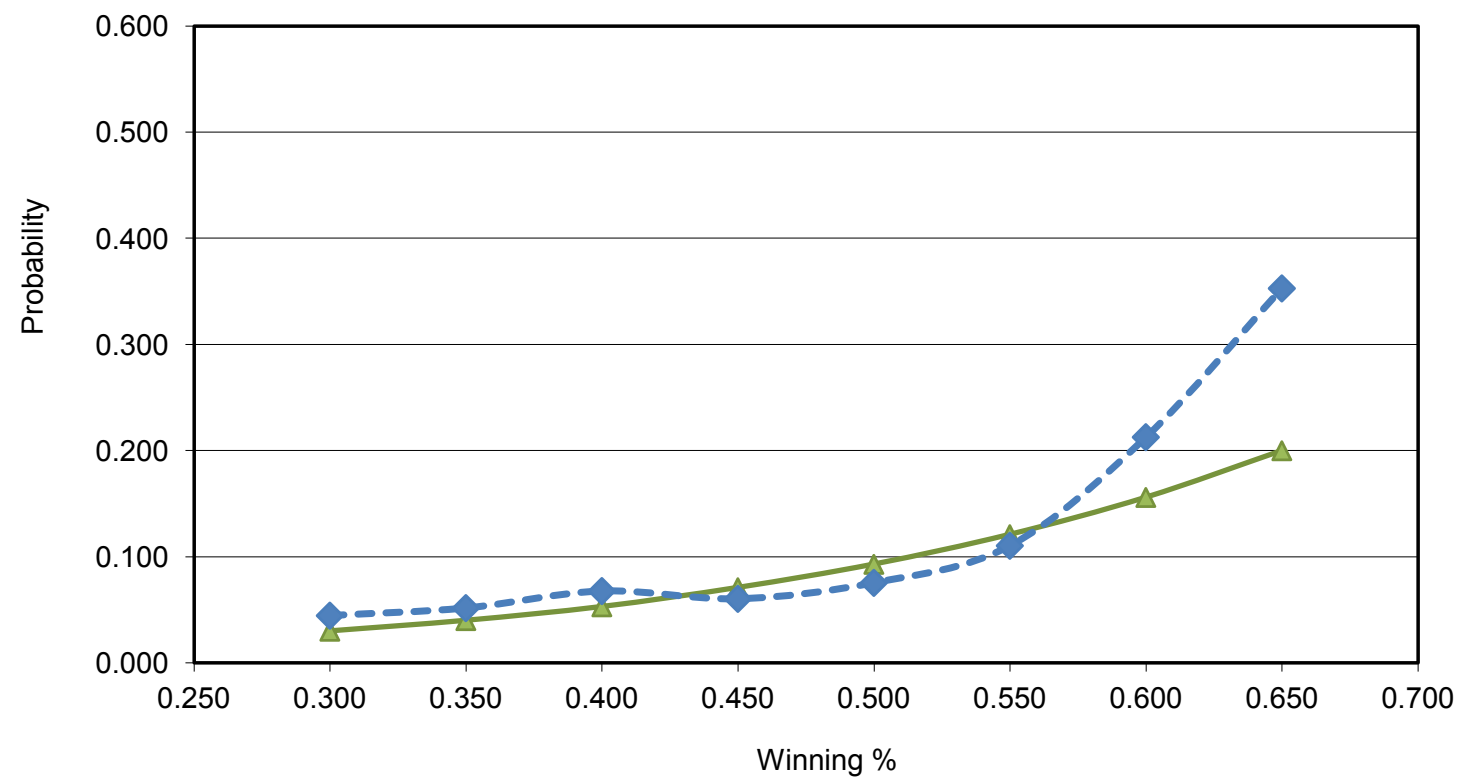

Figure 2: Probability that an ex-Major League Baseball manager will be hired. 
representing 14 wins over 162 games) halves the hazard of dismissal $(0.49=\exp [-7.86 \times 0.09])$. The addition of performance measures leads to a dramatic improvement in goodness of fit and sharpens the effects of employment tenure (ordinarily a beneficiary of unobserved heterogeneity). Effects of team performance are strong and statistically significant when we replace the team's most recent outcomes (model 2) with its average record over the manager's tenure (model 3) and the record of all teams managed by the incumbent over his career (model 4).

Of course, there is much collinearity here because many managerial careers are short and teams show considerable stability in year-to-year performance. The most telling analysis is therefore model 5 , which examines the simultaneous effects of performance over several durations. Wonloss record in the most recent period dominates this analysis, and in fact its coefficient increases in absolute terms by about 75 percent (from -7.8 to -13.6). Won-loss record over the manager's tenure switches signs, becoming a positive predictor of firing once we control for outcomes in the most recent period. Performance over one's career as a whole - which reflects a long-term form of vicarious feedback, because much of this experience is with other teams - has no effect once we control for the manager's record in his current position.

The temporal structure of performance feedback suggests a calculus of evolving expectations. High levels of performance over a manager's tenure raise the standard by which the current season is judged. Managers whose teams fight to an even record are credited with turning the club around if prior campaigns had ended dismally but are blamed for a collapse if the club had previously been a champion. Supplementary analyses that examine performance at defined lags confirm this interpretation. Most tellingly, the impact of lagged performance (at $t-2, t-3, \ldots$ ) is undiminished if a different manager was at the helm, demonstrating that it is the trajectory of the team and not the manager that is consequential. Although we explicitly model the role of evolving expectations, Table 2 provides substantial evidence that experiential feedback adjusts for the organization's recent history.

The second set of columns in Table 2 presents correlative analyses of hiring. Attention to vi- cariously observed outcomes is apparent: a good performance record enhances an ex-manager's chance of regaining the helm of a major league ballclub. A 1 standard deviation rise in the skipper's most recent campaign multiplies the hazard by 1.45 - a smaller effect than in firing but substantial nevertheless. Temporally distant outcomes retain influence as well. When we examine the effects of performance at all three durations, the candidate's most recent results and his record across his career - the manager's entire body of work, so to speak - both have strong and statistically significant effects. Indeed, the latter coefficient is considerably larger in magnitude. A career's worth of good outcomes counts for more than the most recent season's results where hiring is concerned, whereas in firing, it counts for little or nothing.

Supplementary analyses (not shown) that examine the chance of being hired within a year of leaving one's prior position provide additional insight. Recent performance dominates the first probability - managers coming off a strong season were often snapped up before the next season began. Career performance was by contrast the key determinant of the length of the unemployment spell for those individuals who waited more than a year for the phone to ring. Last year's campaign looms large in the following postseason, but as this memory becomes less vivid, executives are likely to consider the manager's lifetime achievements the best index of his ability.

\section{Salience of Success and Failure}

A second set of analyses examines relative sensitivity to success and failure. This issue cannot be examined in the preceding framework, which enforces proportionately equal effects across the outcome range. We thus examine organizational performance by tracking distinct responses to highly positive or negative outcomes. Dramatic success is measured as the winning of a divisional or pennant title, dramatic failure as occupation of the cellar (i.e., a last-place finish). Durational measures give the fraction of seasons when these extraordinary triumphs and collapses occur.

Table 3 relates the occurrence of these extreme outcomes to managerial firing and hiring. Estimated coefficients are all in the expected direction - winning the division, pennant, 


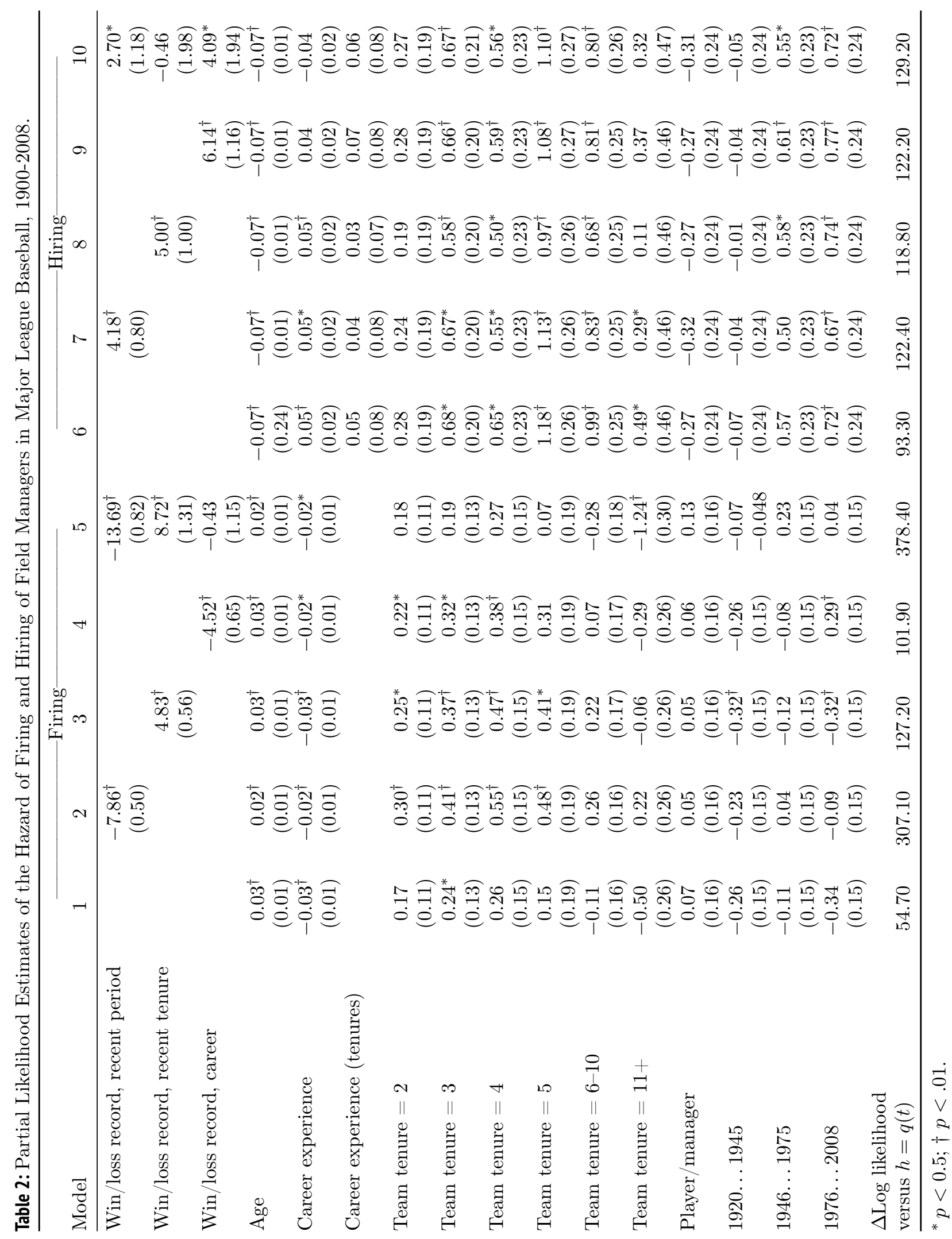


or World Series sharply decreases the likelihood of being fired and increases the probability of gaining a new post, whereas last-place finishes are associated with the loss of one's current position and difficulty in obtaining another one. Temporal dynamics mirror those observed in Table 2. In the case of firing, dramatic success and failure in the most recent period dominate earlier outcomes; sitting managers neither gain security from dramatic success in prior years nor pay a penalty for failure in the past. In the case of hiring, performance over the manager's career has the largest estimated effect, once again in company with a substantial impact of recent results.

What about relative sensitivity to success and failure? The case of managerial firing suggests an almost exact balance between the two. The advantage gained by winning a title is equal to the disadvantage incurred if one's team resides in the cellar (coefficients of -0.72 and 0.73 , which correspond to a halving and doubling of the baseline hazard, respectively). Where hiring is concerned, by contrast, teams seek to reproduce the conditions of each other's success while evidencing little concern with avoiding their failures. The accumulation of divisional, league, and "world" titles speeds reentry into the managerial ranks, while no hiring penalty is applied for time served in the cellar.

\section{Adjustment for Expectations}

A third set of analyses examines the impact of evolving expectations. To do so, we measure performance deviations from historically and socially defined targets (Greve 1998). Historical expectations are defined (see Eq. (1)) as a weighted sum of prior performance. The social expectation is the average performance of the organization's peers, which is (on a reasonable first approximation) 50 percent. Like Greve (1998), we examine sensitivity to deviations from targets and differentials based on whether the organization is above or below its target.

Table 4 shows that expectations based on past performance play a key role in managerial dismissal. Model 1 finds teams to be highly sensitive to the discrepancy between current and prior outcomes; a small shortfall translates into a large increase in the estimated probability of exit. Model 2 shows that this effect is robust when we simultaneously consider the effects of the team's record relative to the social average of 0.500 . While adjustment for past performance carries somewhat greater weight, the two operate in complementary fashion. Teams are most likely to fire their managers when they are doing badly relative to both historical and social targets.

Where hiring is concerned, by contrast, the estimated impact of history-adjusted performance is small and unstable. The positive updating parameter $\alpha$ estimated in model 1 turns negative once we include performance relative to the team's social target. Why would managers who had overseen a relative decline in their clubs' fortunes hire more quickly than those whose teams had improved? We suspect that this once again reflects an emulative calculus by which clubs seek to attract proven winners.

Models 3 and 6 revisit the relative salience of positive and negative outcomes. Firing probabilities are linearly related to the performance of teams with losing records but insensitive to increments to performance above the 0.500 mark. By contrast, hiring is more sensitive to performance above the social target than below it. This result is consistent with the finding in Table 3 that success plays a larger role in vicarious feedback than does failure, though the difference in coefficient magnitudes is not statistically significant (see Greve [2003:126] for the structure of this test).

Figures 3 and 4 summarize the complex effects of team performance relative to expectations. Performance relative to historical expectations has a large impact on firing but a weak and directionally suspect effect on hiring. Performance below the social target of a 0.500 season affects both decisions in roughly the same way, but only hiring is influenced by outcomes above that level. In sum, hiring and firing are both grounded in observed performance, but the two processes are calibrated by different targets and responsive to different ranges of outcomes.

\section{Summary of Findings}

This article has studied the fine structure of experiential and vicarious feedback reflected in the firing and hiring of MLB managers. Differences between the paired processes are robust and sig- 


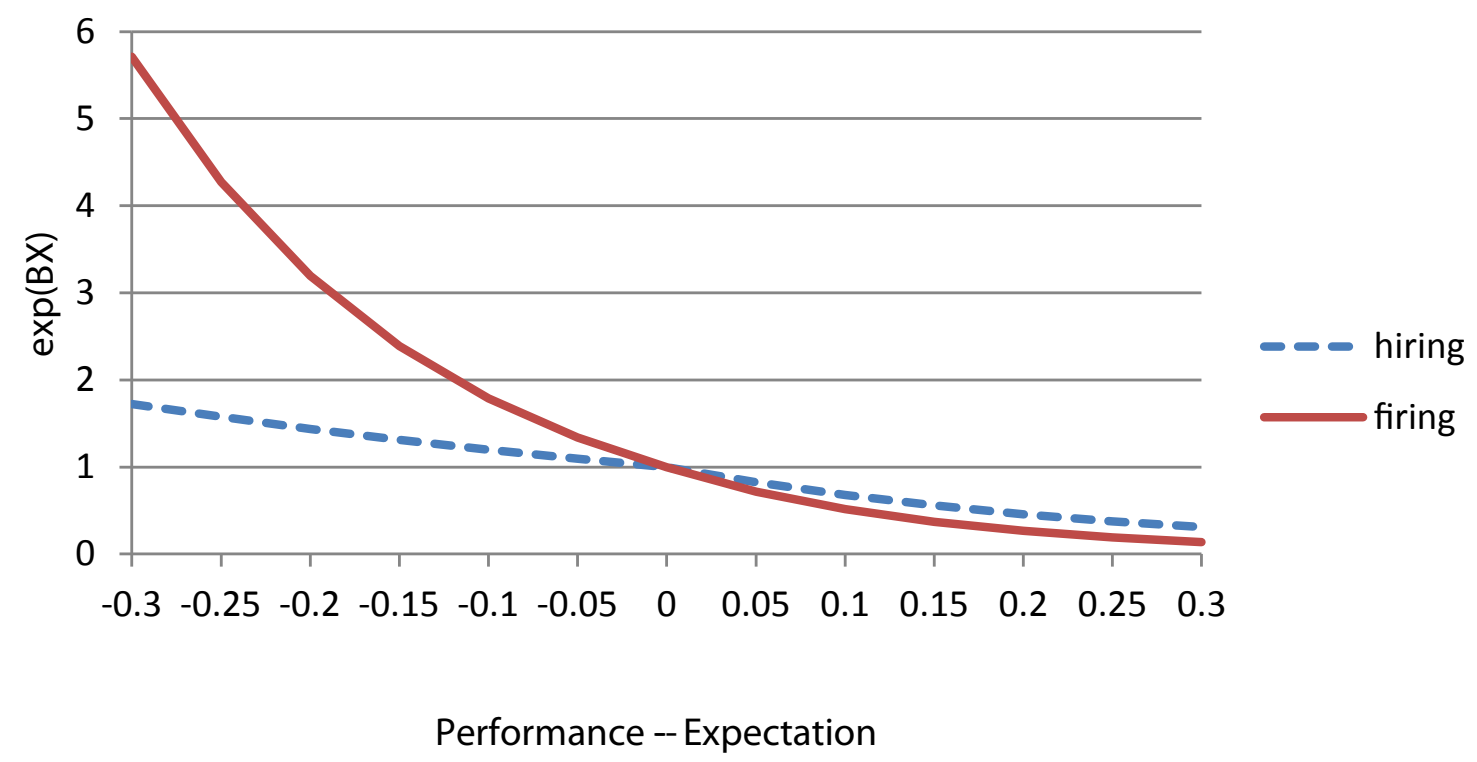

Figure 3: Estimated hazard multipliers for performance relative to historical expectation.

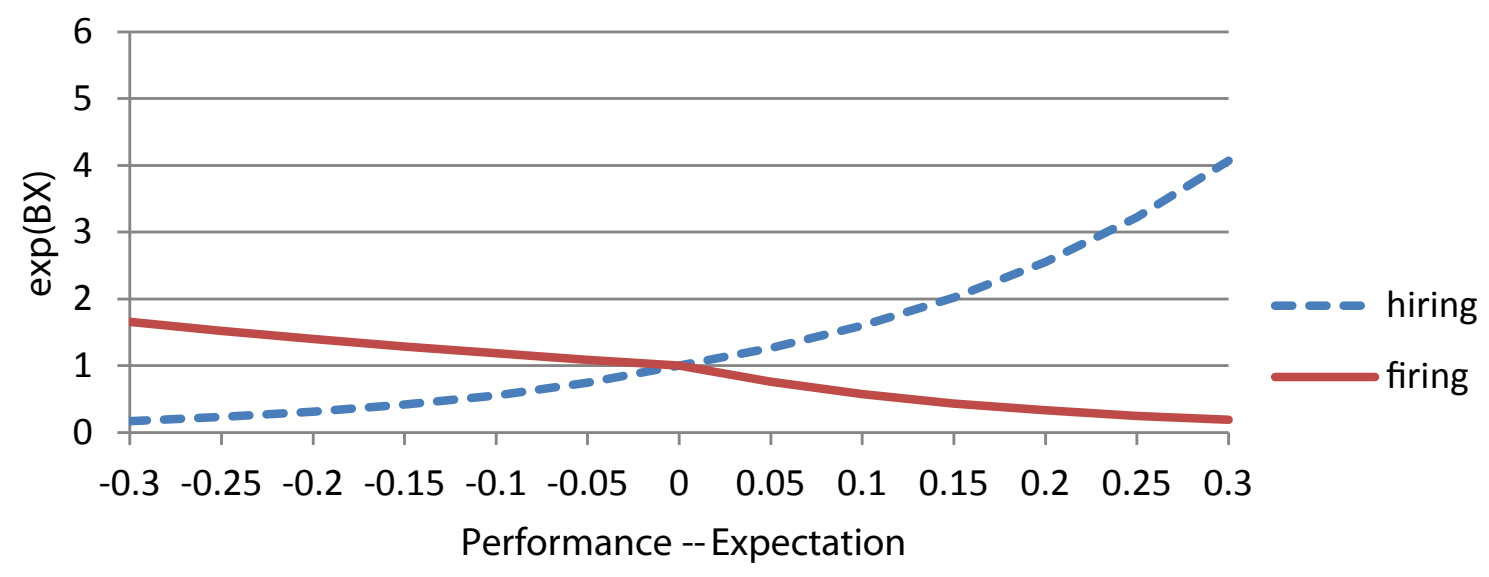

Figure 4: Estimated hazard multipliers for performance relative to social expectation (win/loss record of .500). 
Table 3: Partial likelihood estimates of the hazard of firing and hiring field managers in Major League Baseball, 1900-2008

\begin{tabular}{|c|c|c|c|c|c|c|c|c|}
\hline \multirow[b]{2}{*}{ Model } & \multicolumn{4}{|c|}{-Firing } & \multicolumn{4}{|c|}{-Hiring- } \\
\hline & 1 & 2 & 3 & 4 & 5 & 6 & 7 & 8 \\
\hline Title, recent period & $\begin{array}{r}-0.81^{\dagger} \\
(0.21)\end{array}$ & & & $\begin{array}{r}-0.72^{\dagger} \\
(0.27)\end{array}$ & $\begin{array}{c}0.99^{\dagger} \\
(0.23)\end{array}$ & & & $\begin{array}{r}0.64^{*} \\
(0.32)\end{array}$ \\
\hline Last place, recent period & $\begin{array}{c}0.75^{\dagger} \\
(0.14)\end{array}$ & & & $\begin{array}{r}0.73^{\dagger} \\
(0.21)\end{array}$ & $\begin{array}{c}-0.29 \\
(0.16)\end{array}$ & & & $\begin{array}{c}-0.11 \\
(0.21)\end{array}$ \\
\hline Titles/year, tenure & & $\begin{array}{r}-0.86^{\dagger} \\
(0.27)\end{array}$ & & $\begin{array}{c}0.43 \\
(0.50)\end{array}$ & & $\begin{array}{c}0.67^{\dagger} \\
(0.19)\end{array}$ & & $\begin{array}{c}-0.29 \\
(0.47)\end{array}$ \\
\hline Last place/year, tenure & & $\begin{array}{r}0.66^{\dagger} \\
(0.17)\end{array}$ & & $\begin{array}{c}-0.03 \\
(0.37)\end{array}$ & & $\begin{array}{c}-0.31 \\
(0.18)\end{array}$ & & $\begin{array}{c}-0.07 \\
(0.20)\end{array}$ \\
\hline Title/year, career & & & $\begin{array}{r}-1.21^{\dagger} \\
(0.35)\end{array}$ & $\begin{array}{r}-0.99 \\
(0.55)\end{array}$ & & & $\begin{array}{c}1.27^{\dagger} \\
(0.29)\end{array}$ & $\begin{array}{c}1.08^{*} \\
(0.49)\end{array}$ \\
\hline Last place/year, career & & & $\begin{array}{c}0.62^{\dagger} \\
(0.19)\end{array}$ & $\begin{array}{c}0.06 \\
(0.34)\end{array}$ & - & - & $\begin{array}{c}-0.44 \\
(0.26)\end{array}$ & $\begin{array}{r}-0.28 \\
(0.35)\end{array}$ \\
\hline$\Delta \log$ likelihood versus $h=q(t)$ & 80.90 & 61.08 & 59.01 & 85.27 & 113.92 & 108.19 & 118.23 & 123.05 \\
\hline
\end{tabular}

Note: Models include all covariates shown in Table 2 (age, length of most recent tenure, player/manager, and historical period); coefficients not displayed.

${ }^{*} p<.05 ; \dagger p<.01$.

nificant. First, experiential feedback is driven by a short-term orientation, whereas vicarious feedback shows limited temporal discounting. The organization's recent performance dominates all analyses of firing. Teams ask managers, what have you done for me lately? When organizations make hiring decisions, by contrast, they take the longer view. Recent events are less telling because someone else's ox was gored, and managers are judged as much by their whole body of work as by last year's outcome.

Second, vicarious feedback is dominated by dramatic success, whereas experiential feedback is keyed to the full outcome range. The direction of this difference is in keeping with the qualitative asymmetry we hypothesized, though the evidence for failure bias in experiential feedback is mixed - models of history-based expectations suggest greater sensitivity to losing campaigns than winning ones, but dramatic success through title victories benefit managers to approximately the same degree that last-place finishes harm them. On the vicarious side of the ledger, a powerful success bias is evident in all analyses. Hiring rates rise markedly for the managers of highly successful teams (Figure 2); winning a title is associated with improved chances of renewed employment, whereas time in the cellar does not generate any penalty; and increments to performance above 0.500 benefit managers more than decrements below 0.500 cost them.

Lastly, only experiential feedback shows a clear pattern of adjustment for historically evolving expectations. In Table 2, a manager's chance of retaining his position falls with success over his tenure with the team, which raises the stakes for the current year's campaign. Table 4 shows performance relative to historical expectations to be the strongest single driver of firing decisions. Sitting managers are rewarded for season-to-season gains and punished for relative decline. By contrast, there is no coherent pattern of adjustment for history-based expectations in vicarious feedback. Managers are hired because their teams won, not because they did better than expected.

\section{Discussion}

Demonstration that the employability of baseball managers rises and falls with the team's fortunes will come as no surprise to anyone with a mod- 
Table 4: Expectations-based models: Partial likelihood estimates of the hazard of firing and hiring field managers in Major League Baseball, 1900-2008

\begin{tabular}{|c|c|c|c|c|c|c|}
\hline \multirow[b]{2}{*}{ Model } & \multicolumn{3}{|c|}{ Firing } & \multicolumn{3}{|c|}{-Hiring-_ } \\
\hline & 1 & 2 & 3 & 4 & 5 & 6 \\
\hline Won/loss record - historical expectation & $\begin{array}{r}-9.59^{\dagger} \\
(0.60)\end{array}$ & $\begin{array}{r}-5.99^{\dagger} \\
(0.78)\end{array}$ & & $\begin{array}{r}3.29^{\dagger} \\
(0.63)\end{array}$ & -25546 & \\
\hline Won/loss record -.5 & & $\begin{array}{r}-4.41^{\dagger} \\
(0.67)\end{array}$ & & $\begin{array}{r}4.90^{\dagger} \\
(0.94)\end{array}$ & & \\
\hline Won/loss record - historical expectation $(>0)$ & & & $\begin{array}{r}-6.45^{\dagger} \\
(1.87)\end{array}$ & & & $\begin{array}{r}-4.31 \\
(2.35)\end{array}$ \\
\hline Won/loss record - historical expectation $(<0)$ & & & $\begin{array}{r}-5.79^{\dagger} \\
(1.01)\end{array}$ & & & $\begin{array}{r}-1.33 \\
(1.62)\end{array}$ \\
\hline Won/loss record $-.500(>0)$ & & & $\begin{array}{c}-2.08 \\
(1.52)\end{array}$ & & & $\begin{array}{r}5.74^{\dagger} \\
(1.97)\end{array}$ \\
\hline Won/loss record $-.500(<0)$ & & & $\begin{array}{r}-5.40^{\dagger} \\
(0.89)\end{array}$ & & & $\begin{array}{c}4.74^{\dagger} \\
(1.49)\end{array}$ \\
\hline$A$ & 0.26 & 0.56 & 0.56 & 0.03 & 0.99 & 0.91 \\
\hline$\Delta \log$ likelihood versus $h=q(t)$ & 294.30 & 320.60 & 322.80 & 77.80 & 83.00 & 84.00 \\
\hline
\end{tabular}

Note: Models include all covariates shown in Table 2 (age, length of most recent tenure, player/manager, and historical period); coefficients not displayed.

${ }^{*} p<.05 ; \dagger p<.01$.

icum of familiarity with America's national pastime. We believe, however, that asymmetries in the fine structure of performance feedback - rates of temporal discounting, relative attention to success versus failure, and history-based adjustmentshould be of interest to baseball aficionados and students of organizations alike. Of even greater appeal to the latter group may be the promise of a sociologically interpretive (or "institutional") analysis of performance feedback. Organizational leaders seek to hire capable managers, but they also wish to act in ways that build rather than erode support among their stakeholders. When enacting an effective display of rationality, an organization's own successes and failures present them with a different set of cues than the ones generated by outcomes elsewhere.

An institutional perspective on managerial hiring and firing is most useful in contexts where outcomes are clearly delineated, audiences are closely attentive to organizational performance, managers are visible and dispensable, and culture celebrates individual responsibility. While baseball managers arguably provide a textbook example, political leaders and corporate executives face similar conditions (see Hibbs 2000; Wiesen- feld, Wurthmann, and Hambrick 2008). Logics of accountability and emulation presumably shape organizational action in other domains as well, such as the maintenance or dissolution of interorganizational ties (Jensen 2006) and the adoption and abandonment of innovations (Strang 2010).

\section{What Biases Appear in Experiential versus Vicarious Feedback?}

One strength of feedback models is that they permit not only description but prescription; we can identify the kinds of mistakes that a given decision rule is prone to commit. Thus Levinthal and March (1993) identified the myopia of building too narrowly on recent events and local events; Strang and Macy (2001) the faddish cycles generated by rapt emulation of success; Greve (2002) the costs of updating aspirations too quickly; and Denrell (2003) the systematic errors generated by undersampling failure. Learning researchers often offer the Zen-like counsel that one can improve performance by becoming less performance oriented.

The patterns of experiential and vicarious feedback observed here make classic but differ- 
ent errors. Experiential feedback updates with alarming speed, throwing away valuable information about managerial performance in all but the very recent past. Rapid updating is exacerbated by attention to short-run shifts in direction, which are high variance and in the limit nearly indistinguishable from a random walk. Vicarious feedback retains more information along a temporal dimension but suffers from marked imbalance of attention to success to the virtual exclusion of failure.

The forms of performance feedback observed here are thus incompatible with the view that one type of feedback is "rational," whereas the other is biased by social factors. Both experiential and vicarious feedback discard information that would plausibly assist leaders in making better choices; experiential feedback gives minimal attention to temporally distant outcomes, whereas vicarious feedback overlooks instances of failure. The focus in firing on recent events ("what have you done for me lately?") is not more or less rational than the focus in hiring on success ("are you a proven winner?") - it is differently rational.

The hiring and firing rules documented here are inconsistent in the sense that some outcomes render a sitting manager more likely to retain his position while diminishing his prospects in a subsequent hiring market. For example, incremental improvement is associated with job security among job holders, whereas job seekers benefit if their track records feature dramatic successes and failures. Holding average outcomes and other factors constant, teams would hold on to the first type of manager longer than the second but hire the second over the first when filling a vacancy.

\section{Conclusion}

This article has not asked whether and to what extent baseball managers influence team outcomes (for a debate, see Grusky [1960] vs. Gamson and Scotch [1964]). The performance feedback framework does not assert that organizations draw correct inferences from history; it argues instead that decisions are shaped by realized outcomes in simple ways that can be modeled. Much uncontrolled observation suggests that the impact of baseball managers on collective success is prob- ably small, that general managers and owners believe this, that fans and other stakeholders believe this, and that all of these interested parties believe that the other parties believe this. In a highly competitive setting, however, small does not mean insignificant, as those who have endured too many boneheaded decisions - and managers - will readily testify. Our claim is not that executives are uninterested in making discriminating personnel decisions but rather that their choices are framed by normative orientations and, concretely, by logics of accountability and emulation.

We contend that models of performance feedback based on bounded rationality can be usefully augmented by an institutional perspective - what we might whimsically call a marriage of the earlier and later March. Culturally savvy leaders respond to outcomes in ways that dramatically display rationality to their audience. These displays are particularly salient when we consider why responses to identical records of performance depend on whether they are experienced directly or observed vicariously; the first take the form of a morality play, whereas the latter enact a search for the secrets of success. Decision-making scripts and the career trajectories they generate provide a rich vein for students of organizations to explore and exploit.

\section{References}

Baum, Joel A. C. and Kristina B. Dahlin. 2007. "Aspiration Performance and Railroads' Patterns of Learning from Train Wrecks and Crashes." Organization Science 18:368-85. http://dx.doi.org/10.1287/ orsc. 1060.0239

Boeker, Warren. 1992. "Power and Managerial Dismissal: Scapegoating at the Top." $A d$ ministrative Science Quarterly 37:400-421. http://dx.doi.org/10.2307/2393450

Chuang, You-Ta and Joel A. C. Baum. 2003. "It's All in the Name: Failure-Induced Learning by Multiunit Chains." Administrative Science Quarterly 48:33-59. http://dx.doi.org/10 2307/3556618

Cyert, Richard M. and James G. March. 1963. A Behavioral Theory of the Firm. Saddle River, NJ: Prentice Hall. 
Denrell, Jerker. 2003. "Vicarious Learning, Undersampling of Failure, and the Myths of Management." Organization Science 14:22743. http://dx.doi.org/10.1287/orsc.14 2.227 .15164

Denrell, Jerker and James G. March. 2001. "Adaptation as Information Restriction: The Hot Stove Effect." Organization Science 12:523-38. http://dx.doi.org/10.1287/ orsc.12.5.523.10092

DiMaggio, Paul J. and Walter W. Powell. 1983. "The Iron Cage Revisited: Institutional Isomorphism and Collective Rationality in Organizational Fields." American Sociological Review 48:147-60. http://dx.doi.org/10 2307/2095101

Feldman, Martha S. and James G. March. 1981. "Information in Organizations as Signal and Symbol." Administrative Science Quarterly 26:171-86. http://dx.doi.org/10.2307/ 2392467

Fredrickson, James W., Donald C. Hambrick, and Sara Baumrin. 1988. "A Model of CEO Dismissal." Academy of Management Review 13:255-70.

Gamson, William A. and Norman A. Scotch. 1964. "Scapegoating in Baseball." American Journal of Sociology 70:69-72. http: //dx.doi.org/10.1086/223739

Greve, Henrich R. 1998. "Performance, Aspirations, and Risky Organizational Change." Administrative Science Quarterly 43:58-86. http://dx.doi.org/10.2307/2393591

Greve, Henrich R. 2002. "Sticky Aspirations: Organizational Time Perspective and Competitiveness." Organization Science 13:117. http://dx.doi.org/10.1287/orsc.13 1.1 .540

Greve, Henrich R. 2003. Organizational Learning from Performance Feedback. London: Cambridge University Press. http://dx.doi org/10.1017/CB09780511615139

Grusky, Oscar. 1960. "Administrative Succession in Formal Organizations." Social Forces 39:105-15. http://dx.doi.org/10. $2307 / 2574148$

Haunschild, Pamela R. and A. S. Miner. 1997. "Modes of Interorganizational Imitation: The Effects of Outcome Salience and Uncertainty."
Administrative Science Quarterly 41:472-500. http://dx.doi.org/10.2307/2393735

Haveman, Heather A. 1993. "Follow the Leader: Mimetic Isomorphism and Entry into New Markets." Administrative Science Quarterly 38:593-627. http://dx.doi.org/10.2307/ 2393338

Hibbs, Douglas A., Jr. 2000. "Bread and Peace Voting in U.S. Presidential Elections." Public Choice 104:149-80. http://dx.doi.org/10 1023/A: 1005292312412

Jensen, Michael. 2006. "Should We Stay or Should We Go? Accountability, Status Anxiety, and Client Defections." Administrative Science Quarterly 51:97-128. http:// dx.doi.org/10.2189/asqu.51.1.97

Kesner, Idalene F. and Terrence C. Sebora. 1994. "Executive Succession: Past, Present, and Future." Journal of Management 20:327-72. http://dx.doi.org/10.1016/ 0149-2063(94)90019-1

Khurana, Rakesh. 2002. Searching for a Corporate Savior. Princeton, NJ: Princeton University Press.

Kim, Ji-Yub and Anne S. Miner. 2007. "Vicarious Learning from the Failures and NearFailures of Others: Evidence from the U.S. Commercial Banking Industry." Academy of Management Journal 50:687-714. http:// dx.doi.org/10.5465/AMJ . 2007.25529755

Lerner, Jennifer S. and Philip E. Tetlock. 1999. "Accounting for the Effects of Accountability." Psychological Bulletin 125:255-75. http://dx.doi.org/10.1037/ 0033-2909.125.2.255

Levinthal, Daniel A. and James G. March. 1993. "The Myopia of Learning." Strategic Management Journal 14:95-112. http://dx.doi org/10.1002/smj.4250141009

Manns, Curtis and James G. March. 1978. "Financial Adversity, Internal Competition, and Curriculum Change in a University." Administrative Science Quarterly 23:541-52. http: //dx.doi.org/10.2307/2392579

March, James G. and Herbert A. Simon. 1958. Organizations. Oxford: Blackwell.

Meindl, James R., Sanford B. Ehrlich, and Janet M. Dukerich. 1985. "The Romance of Leader- 
ship." Administrative Science Quarterly 30:78102. http://dx.doi.org/10.2307/2392813

Meyer, John W. and Brian Rowan. 1977. "Institutionalized Organizations: Formal Structure as Myth and Ceremony." American Journal of Sociology 83:340-63. http://dx.doi.org/ $10.1086 / 226550$

Ouchi, William G. and Mary Ann Maguire. 1975. "Organizational Control: Two Functions." Administrative Science Quarterly 20:559-69. http://dx.doi.org/10.2307/2392023

Puffer, Sheila M. and Joseph B. Weintrop. 1991. "Corporate Performance and CEO Turnover: The Role of Performance Expectations." Administrative Science Quarterly 36:1-19. http: //dx.doi.org/10.2307/2393427

Schwab, Andreas. 2007. "Incremental Organizational Learning from Multilevel Information Sources: Evidence for CrossLevel Interactions." Organization Science 18:233-51. http://dx.doi.org/10.1287/ orsc.1060.0238

Sports Reference LLC. 2008. "Major League Statistics and Information." http://www baseball-reference.com/.

Staw, Barry M., Lance E. Sandelands, and Jane E. Dutton. 1981. "Threat Rigidity Effects in Organizational Behavior: AMultilevel Analysis." Administrative Science Quarterly 26:501-24. http://dx.doi.org/10.2307/2392337

Staw, Barry M., Pamela I. McKechnie, and Sheila M. Puffer. 1983. "The Justification of Organizational Performance." Administrative Science Quarterly 28:582-600. http: //dx.doi.org/10.2307/2393010

Strang, David. 2010. Learning by Example. Princeton, NJ: Princeton University Press.

Strang, David and Michael W. Macy. 2001. "In Search of Excellence: Fads, Success Stories, and Adaptive Emulation." American Journal of Sociology 107:147-82. http://dx.doi org/10.1086/323039

Wiesenfeld, Batia M., Kurt A. Wurthmann, and Donald C. Hambrick. 2008. "The Stigmatization and Devaluation of Elites Associated with Corporate Failures: A Process Model." Academy of Management Review 33:231-51. http://dx.doi.org/10.5465/ AMR . 2008. 27752771
Zuckerman, Ezra W. 1999. "The Categorical Imperative: Securities Analysts and the Illegitimacy Discount." American Journal of Sociology 104:1398-1438. http://dx.doi.org/ $10.1086 / 210178$

Acknowledgements: Previous versions of this article were presented at the annual meetings of the American Sociological Association and the Academy of Management and at Harvard University, Imperial College, and the University of Chicago. We are grateful to Joel Baum, Matthew Bothner, Ronald Burt, Frank Dobbin, Peer Fiss, Henrich Greve, Martin Kilduff, James March, Nelson Phillips, Nandini Rajagopalan, Ray Reagans, and Ezra Zuckerman for their helpful suggestions. Direct correspondence to David Strang, Department of Sociology, Cornell University.

David Strang: Cornell University. E-mail: ds20@ cornell.edu.

Kelly Patterson: University of Southern California. E-mail: klpatter@marshall.usc.edu. 